\title{
An autopsy case of unexpected death due to Addison's disease caused by adrenal tuberculosis
}

Nan Zhao ${ }^{1,2}$, Yutong Gao ${ }^{1,2}$, Chunsheng Ni ${ }^{1,2}$, Danfang Zhang ${ }^{1,2}$, Xiulan Zhao ${ }^{1,2}$, Yanlei Li ${ }^{1,2}$ and Baocun Sun ${ }^{1,2^{*}}$

\begin{abstract}
Background: Adrenal tuberculosis is difficult to diagnose due to non-specific symptom. Unexpected death due to adrenal insufficiency after trauma surgery is rare.

Case presentation: A 45-year-old man, who was admitted to hospital because of trauma to the right hand, died unexpectedly on the 13th day after replantation of amputated fingers. He was diagnosed with brain edema and diluted hyponatremia. Autopsy and histopathologic examination revealed severe brain edema combined with cerebellar tonsillar hernia, extensive destruction of adrenal gland caused by bilateral adrenal tuberculosis and right lung invasive pulmonary tuberculosis.

Conclusions: Trauma and pulmonary tuberculosis complicated with adrenal tuberculosis induced the adrenal crisis, which eventually lead to severe cerebral edema and hernia, and finally death from respiratory and circulatory failure. This autopsy and histopathologic examination suggested a possible pathophysiologic mechanism of sudden death due to diluted hyponatremia after trauma surgery.
\end{abstract}

Keywords: Adrenal crisis, Pulmonary tuberculosis, Adrenal tuberculosis

\section{Introduction}

Thomas Addison first described the clinical presentation of primary adrenocortical insufficiency in 1855 and Trousseau defined an adrenal insufficiency as an Addison's disease (AD) in 1856 [1, 2]. Adrenal insufficiency (AD) continues to present a challenge for patients, their physicians and researchers [3]. Tuberculosis was the most common cause of adrenal insufficiency in the developing countries [4]. According to a retrospective analysis of autopsies and adrenalectomies reviewed by $\mathrm{K} \mathrm{Y}$ Lam and C Y Lo, the adrenal gland was the only extrapulmonary organ involved by tuberculosis in 14 of these 55 patients (25\%; 35 men and 20 women).They found

*Correspondence: sunbaocun@aliyun.com

1 Department of Pathology, Tianjin Medical University, No.22 Qixiangtai Road, Heping District, Tianjin 300070, PR China

Full list of author information is available at the end of the article that unexpected and extra-pulmonary tuberculosis such as adrenal tuberculosis has been a common problem [5]. Adrenal tuberculosis is difficult to diagnose due to nonspecific symptoms [6]. The diagnosis is therefore often delayed. The fact that adrenal insufficiency may result not only in poor general condition of the patient, but also death due to adrenal crisis makes it all the more important to address this issue seriously [7]. Evidence on clinical presentation and evaluation of patients with adrenal insufficiency caused by bilateral adrenal tuberculosis is scarce.

Here, we report an unusual case of a patient admitted to hospital because of trauma without obvious clinical symptoms and signs of tuberculosis and adrenal insufficiency who died unexpectedly on the 13th day after finger replantation. This autopsy and histopathologic examination suggested a possible pathophysiologic mechanism of 
sudden death due to adrenal crisis caused by tuberculosis and trauma infection.

\section{Case presentation}

A 45-year-old man, who was urgently admitted to hospital due to bleeding and dysfunction of right hand caused by trauma of the 2nd to 4th fingers. He had an unremarkable medical history and was treated by finger replantation after admission. However, on the 13th day after replantation, the patient fell down after vomiting. The blood pressure $(104 / 70 \mathrm{mmHg}$, reference range: 90-130/60-85 $\mathrm{mmHg}$ ) and glucose levels $(3.9 \mathrm{mmol} / \mathrm{L}$, reference range: $3.5-5.3 \mathrm{mmol} / \mathrm{L}$ ) were normal, while head computed tomography (CT)-scan showed cerebral edema and laboratory examination detected an electrolyte disturbance (Table 1). He was diagnosed with brain edema, diluted hyponatremia and bacterial infection. After seizure, respiratory and cardiac arrest suddenly occurred. Although an aggressive resuscitation attempt was made, he was pronounced dead. To investigate the cause of death, a pathologic autopsy was performed $48 \mathrm{~h}$ later.

At autopsy, the patient was emaciated with dark skin, but without typical hyperpigmentation in the mucosal surfaces. The right hand was swollen with surgical suture and Kirschner wire in the 2nd to 4th fingers; no obvious purulent was present; there were no injuries and surgical incisions in other parts of the body.

There was congestion and swelling in the pulmonary bed; calcification foci (the range is about $1.5 \times 1 \times$ $1 \mathrm{~cm}) \mathrm{can}$ be found in the lower lobe of right lung. Pleural thickening of both lungs was observed. Pulmonary hilar lymph nodes were enlarged. Microscopic examination showed congestion in pulmonary bed and swelling in the alveoli of both lungs, especially the lower lobe of right lung. It also showed caseous necrosis with calcification and granuloma formation in the lower lobe of right lung, pleural fibrous tissue hyperplasia of bilateral lung

Table 1 Laboratory values

\begin{tabular}{lll}
\hline Laboratory test & Value & Reference range \\
\hline $\mathrm{pH}$ & 7.087 & $7.350-7.450$ \\
Sodium & $108.2 \mathrm{mmol} / \mathrm{L}$ & $136.0-145.0 \mathrm{mmol} / \mathrm{L}$ \\
Calcium & $1.030 \mathrm{mmol} / \mathrm{L}$ & $1.150-1.330 \mathrm{mmol} / \mathrm{L}$ \\
Lactic acid & $9.1 \mathrm{mmol} / \mathrm{L}$ & $0.6-1.4 \mathrm{mmo} / \mathrm{L}$ \\
Chlorine & $78.7 \mathrm{mmol} / \mathrm{L}$ & $98.0-107.0 \mathrm{mmol} / \mathrm{L}$ \\
C-reactive protein & $15.03 \mathrm{mg} / \mathrm{L}$ & $0.00-10.00 \mathrm{mg} / \mathrm{L}$ \\
Procalcitonin & $0.73 \mathrm{ng} / \mathrm{L}$ & $0.04-0.50 \mathrm{ng} / \mathrm{L}$ \\
Cortisol & $<1.00 \mathrm{ug} / \mathrm{dL}$ & $5.00-25.00 \mathrm{ug} / \mathrm{dL}$ \\
Adrenocorticotropic hormone & $855.00 \mathrm{pg} / \mathrm{mL}$ & $0.00-46.00 \mathrm{pg} / \mathrm{mL}$ \\
\hline
\end{tabular}

and granulomatous inflammation of hilar lymph nodes (Fig. 1).

The left adrenal gland was $3 \times 2 \times 1.5 \mathrm{~cm}$ in size and $13.0 \mathrm{~g}$ in weight, shown in irregular nodular shape with extensive caseous necrosis and a few residual adrenal gland. There was no obvious right adrenal gland. Microscopic examination showed caseous necrosis with calcification in the left adrenal gland area, anti-acid staining was positive; granulomatous lesions were observed in the right adrenal area, and a little caseous necrosis can be seen in the center (Fig. 2).

The brain was $19 \times 15 \times 6 \mathrm{~cm}$ in size and the cerebellum was $10 \times 8 \times 4 \mathrm{~cm}$ in size. The brain and cerebellum weighed $1446.5 \mathrm{~g}$. Vasodilation and congestion were observed on the surface of meninges; cerebral gyrus was wide and cerebral sulcus was narrow; there was no subarachnoid hemorrhage; both sides of the brain were symmetrical, without bleeding on the section. There were obvious indentation on the right cerebellar tonsils; no bleeding was found in cerebellar section (Fig. 2E). Microscopic examination showed dilation and hyperemia of the blood vessel in subarachnoid, and the perivascular lymphatic space in the brain parenchyma was significantly widened. The nerve fibers were sparse, and the neuron cells were degenerated, showing obvious brain edema changes.

There were no remarkable abnormalities in heart, liver, kidney, spleen and gastrointestinal tract.

\section{Discussion}

We report a patient with tuberculosis-induced adrenal insufficiency (AD), who presented with abnormal electrolytes, but without typical clinical symptoms so that it was ignored by the patient himself. The patient denied medical history when he was brought to hospital because of trauma.

Except for salt craving, the symptoms of primary adrenal insufficiency are rather nonspecific and include weakness, fatigue, musculoskeletal pain, weight loss, abdominal pain, depression and anxiety [6]. As a result, the diagnosis is frequently delayed, resulting in a clinical presentation with an acute lifethreatening adrenal crisis [8]. Majority cases of adrenal insufficiency (AD) in the developed countries are attributed to autoimmune adrenalitis in contrast to the developing countries where tuberculosis is implicated to be the most common cause of adrenal insufficiency [7, 9]. In 2019, tuberculosis remained the most common cause of death from a single infectious pathogen [10]. In China, although the incidence of tuberculosis has decreased in recent years, the country still shares a significant part of the global burden of tuberculosis cases (8.4\%) [10]. People 
A

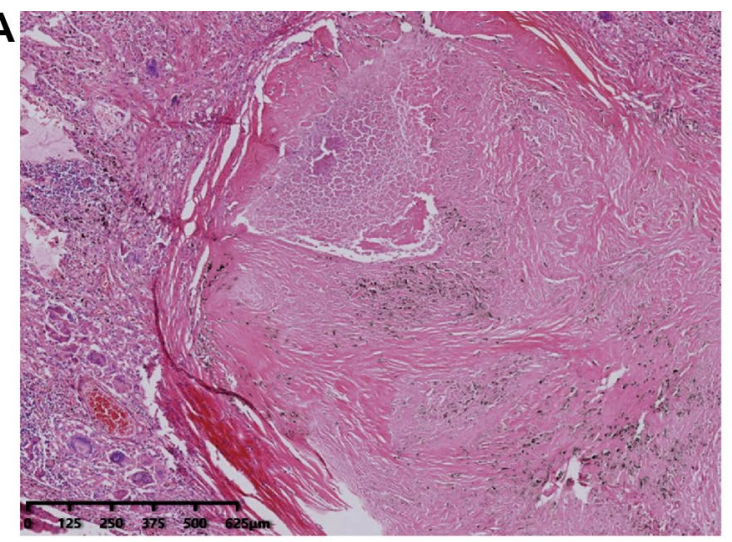

C

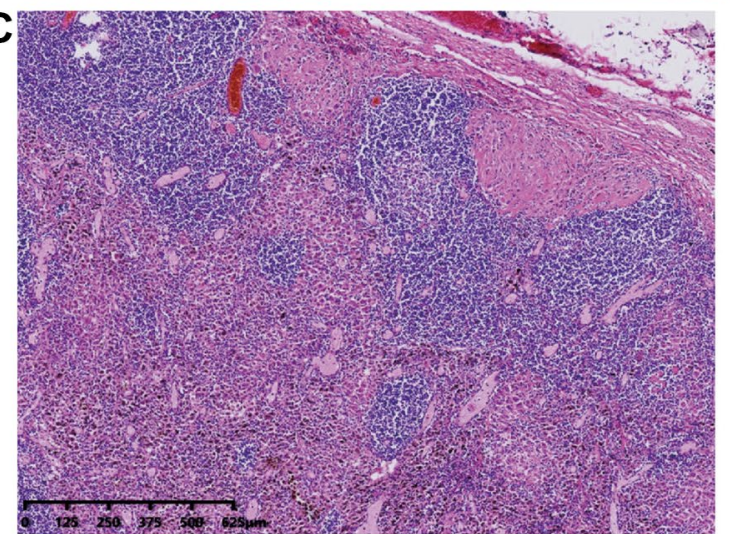

E

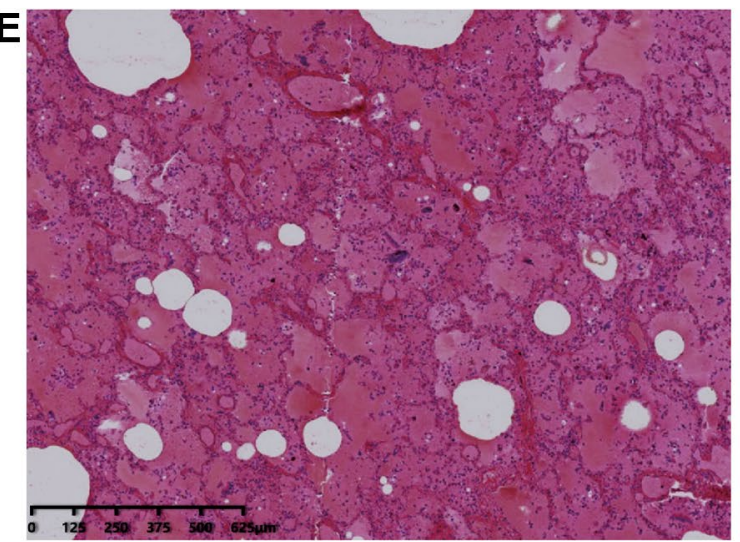

B

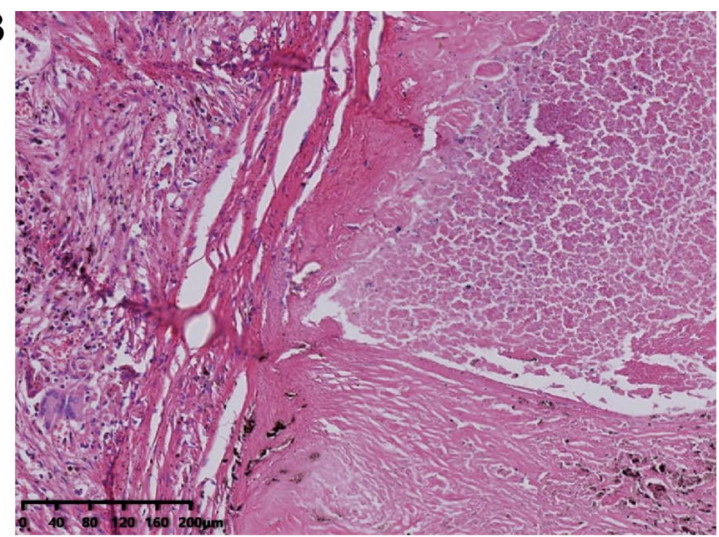

$\mathrm{D}$

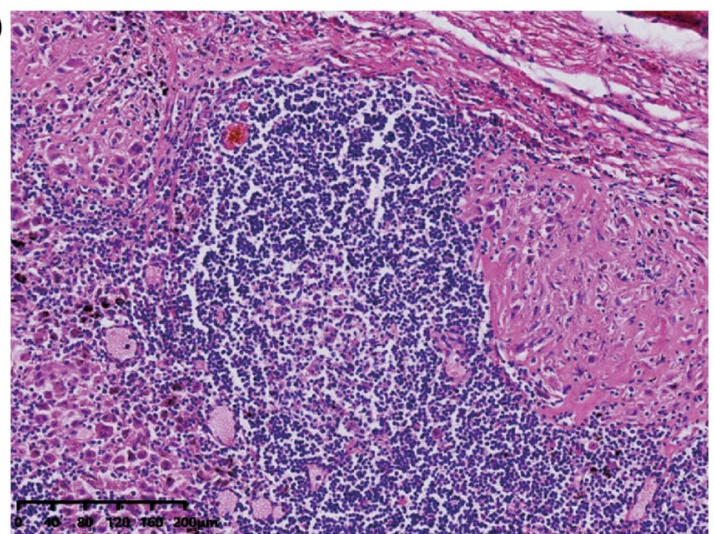

$\mathrm{F}$

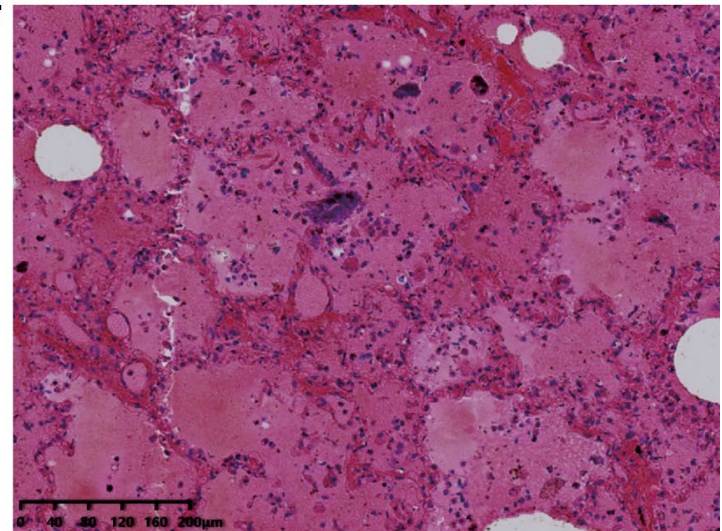

Fig.1 A (HE $4 \times)$ and $\mathbf{B}(H E 10 \times)$ Tuberculosis of right lung. C (HE $4 \times)$ and $\mathbf{D}(H E 10 \times)$ Tuberculosis of pulmonary hilar lymph node. E (HE $4 \times$ ) and $\mathrm{F}(\mathrm{HE} 10 \times)$ Congestion and swelling in pulmonary

living in rural areas, those who were less educated showed a low level of awareness of key knowledge about tuberculosis, leading to a delay in seeking care [11]. Adrenal insufficiency which may be caused by adrenal tuberculosis is a severe and potentially lifethreatening condition related to the central role of glucocorticoids and/or mineralocorticoids in energy, salt, and fluid homeostasis [12]. Laboratory value of the patient in this case showed significant reduction of cortisol and incredible increase of adrenocorticotropic hormone.

We concluded that trauma and pulmonary tuberculosis complicated with adrenal tuberculosis induced the adrenal crisis, which eventually lead to severe cerebral edema and hernia, and finally death from respiratory and circulatory failure. This autopsy and histopathologic examination suggested a possible pathophysiologic mechanism of sudden death due to diluted hyponatremia after trauma surgery. 

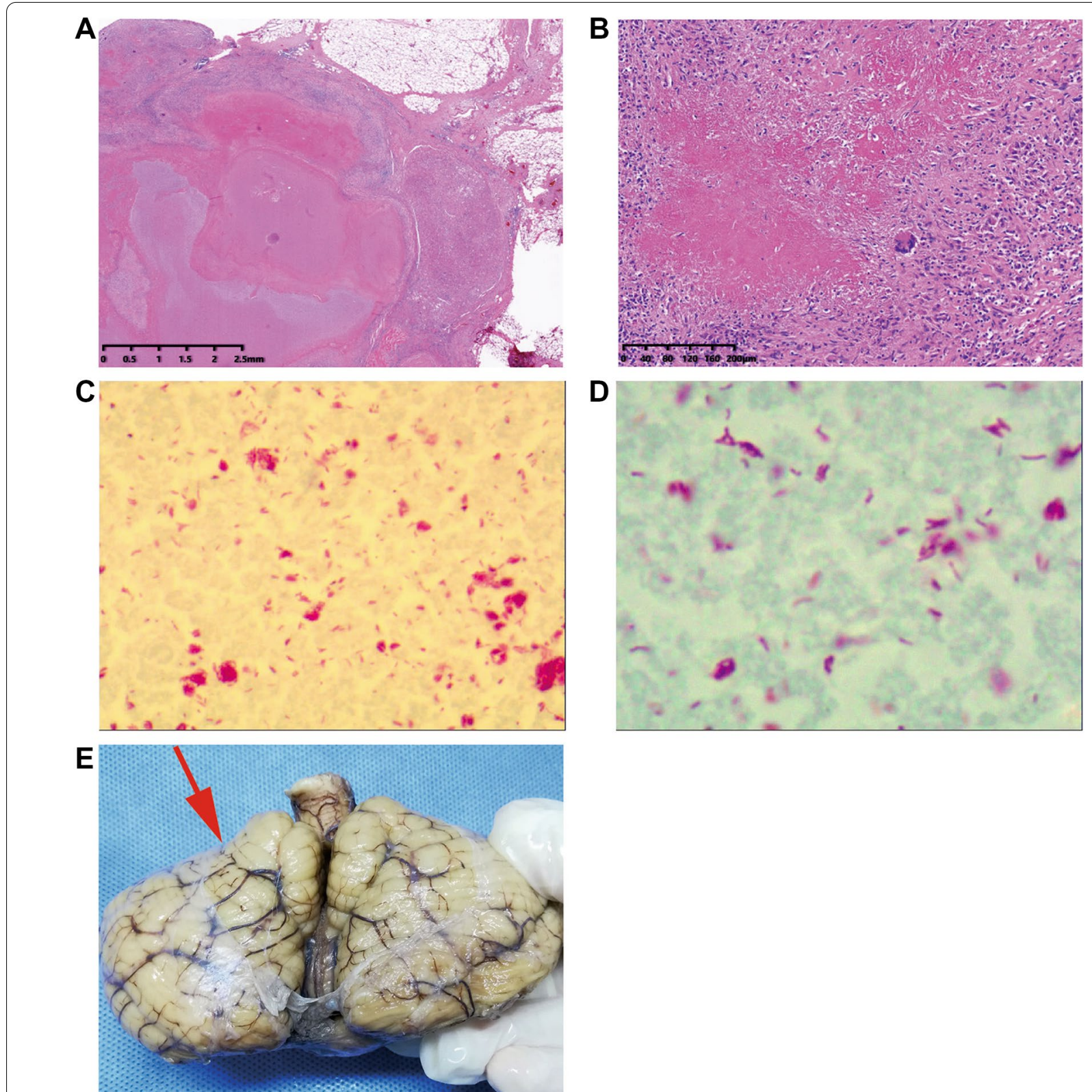

Fig.2 A $(H E 1 \times)$ and B $(H E 10 \times)$ Irregular nodules with caseous necrosis result in extensive destruction of left adrenal gland. C (anti-acid staining $10 \times$ ) and $\mathbf{D}$ (anti-acid staining $100 \times$ ) Tuberculosis of left adrenal gland. E Cerebellar tonsillar hernia (red arrow)

\section{Abbreviations}

CT: Computed tomography; H\&E: Hematoxylin and eosin.

\section{Acknowledgements}

The authors would like to thank our patient and his family for allowing for his case to be presented.

\section{Authors' contributions}

$B S, N Z, Y G, C N, D Z, Y L$ and $X Z$ were responsible for performing the autopsy.

$B S, N Z$ and $Y G$ reviewed the microscopy. NZ was responsible for the literature search and manuscript preparation. BS reviewed the manuscript and provided expert opinion. All authors have read and approved the final manuscript.

\section{Funding}

This study was supported by project of Nature Science Foundation of Tianjin (No. 19JCYBJC25800).

\section{Availability of data and materials}

All data generated or analyzed during this study are included in this published article. 


\section{Declarations}

Ethics approval and consent to participate

Ethical approval was obtained from the Ethical Committee of Tianjin medical university. At the time of death, consent for the autopsy and informed consent was obtained from the family.

\section{Consent for publication}

Not applicable.

\section{Competing interests}

The authors declare that there are no competing interests.

\section{Author details}

${ }^{1}$ Department of Pathology, Tianjin Medical University, No.22 Qixiangtai Road, Heping District, Tianjin 300070, PR China. ${ }^{2}$ Department of Pathology, General Hospital of Tianjin Medical University, Tianjin 300052, China.

Received: 24 June 2021 Accepted: 15 November 2021

Published online: 04 December 2021

\section{References}

1. Addison T. On the constitutional and local effects of disease of the suprarenal capsules. Br Foreign Med Chir Rev. 1856;18:404-13.

2. Betterle C, Dal Pra C, Mantero F, Zanchetta R. Autoimmune adrenal insufficiency and autoimmune polyendocrine syndromes: autoantibodies, autoantigens, and their applicability in diagnosis and disease prediction. Endocr Rev. 2002;23:327-64.

3. Bancos I, Hahner S, Tomlinson J, Arlt W. Diagnosis and management of adrenal insufficiency. Lancet Diabetes Endocrinol. 2015;3:216-26.

4. Yu J, Lu Y, Han B. Primary adrenal insufficiency due to adrenal tuberculosis: a case report. J Int Med Res. 2020;48:300060520980590.

5. Lam KY, Lo CY. A critical examination of adrenal tuberculosis and a 28-year autopsy experience of active tuberculosis. Clin Endocrinol. 2001:54:633-9.

6. Jang SA, Park JH, Lee KA. Primary adrenal and chest wall tuberculosis presenting as an adrenal crisis. QJM. 2017;110:389-90.

7. Sarin BC, Sibia K, Kukreja S. Study of adrenal function in patients with tuberculosis. Indian J Tuberc. 2018;65:241-5.

8. Bleicken B, Hahner S, Ventz M, Quinkler M. Delayed diagnosis of adrenal insufficiency is common: a cross-sectional study in 216 patients. Am J Med Sci. 2010:339:525-31.

9. Parameswaran $V$. Adrenal insufficiency with special reference to tubercuIosis. Indian J Tuberc. 2014:61:103-5.

10. Chakaya J, Khan M, Ntoumi F, Aklillu E, Fatima R, Mwaba P, Kapata N, Mfinanga S, Hasnain SE, Katoto P, Bulabula ANH, Sam-Agudu NA, Nachega JB, Tiberi S, McHugh TD, Abubakar I, Zumla A. Global Tuberculosis Report 2020 - reflections on the Global TB burden, treatment and prevention efforts. Int J Infect Dis. 2021. https://doi.org/10.1016/j.ijid.2021.02.107.

11. Chen X, Wang W, Wang X, Chai C, Liu K, Peng Y, Wang F, Chen B, Jiang J. Public awareness of tuberculosis in Southeast China: a population-based study. Int J Env Res Public Health. 2019. https://doi.org/10.3390/ijerp h16214290.

12. Bornstein SR, Allolio B, Arlt W, Barthel A, Don-Wauchope A, Hammer GD Husebye ES, Merke DP, Murad MH, Stratakis CA, Torpy DJ. Diagnosis and treatment of primary adrenal insufficiency: an endocrine society clinical practice guideline. J Clin Endocrinol Metab. 2016;101:364-89.

\section{Publisher's Note}

Springer Nature remains neutral with regard to jurisdictional claims in published maps and institutional affiliations.
Ready to submit your research? Choose BMC and benefit from:

- fast, convenient online submission

- thorough peer review by experienced researchers in your field

- rapid publication on acceptance

- support for research data, including large and complex data types

- gold Open Access which fosters wider collaboration and increased citations

- maximum visibility for your research: over 100M website views per year

At BMC, research is always in progress.

Learn more biomedcentral.com/submissions 